\title{
Grimy Heritage: Organic Bar Streets in Shanghai and Tokyo
}

\author{
James Farrer \\ Graduate School of Global Studies, Sophia University, Tokyo, Japan \\ Email: jamescfarrer@gmail.com
}

\begin{abstract}
Every city has built environments that are largely regarded as eyesores, for aesthetic, social, or moral reasons. Urban nightlife streets are examples of such 'grimy heritage'. Not only shabby and disorderly, they harbour forms of commercial sex, drinking cultures, and ephemeral nightlife cultures that many city residents and government officials consider undesirable. Sometimes their built forms are regarded as the enemy of genuine heritage architecture, since they obscure more solid, carefully designed structures around them. However, in many cities, organic nightlife streets-developing in such spaces precisely because they were derelict or poorly regulated-serve important social functions as spaces of creativity and community formation. This paper examines the ways that such 'grimy heritage' has developed in Shanghai and Tokyo, using examples from ethnographic research and historical sources, and addressing the question of the contribution of the 'grimy heritage' to authentic, urban social life.
\end{abstract}

KEYWORDS China, cultural governance, Japan, nightlife, night-time economy, urban studies

Received July 15, 2019; accepted September 5, 2019.

\section{Geographies of Grime}

A great city needs a little grime, a dark side, or put another way, if the skyscraper is the representation of a phallic, ascendant modernist striving, the shadowy demimonde of bars and cabarets is an equally potent symbol of the urban feminine modern: a modernism of dangerous and dirty pleasures: the nocturnal, exotic, sexual, and drunken fun that city girls are imagined to get up to (Weinbaum et al. 2008). New York, London, Paris, Shanghai, and Tokyo, all have their glistening towers, and in the shadows of these towers, their famously disreputable entertainment zones. In this paper, I argue that this grimy nightscape is a disregarded feature of urban heritage, and its governance a key distinction in cities' cultural governance. A city that is too clean may be regarded 'sterile', as we often hear about Singapore, a place reputed to have gone too far in eliminating urban grit (Quora 2013). The point of this essay is to discuss the approaches cities take to the governance of geographies of grime by comparing the development and response to the gritty organic bar streets in Shanghai and Tokyo.

First, I introduce some of the conceptual background to this study. Then I outline the development of organic bar streets in both cities. Organic bar streets are unplanned and low-investment nightlife zones that can also be called informal or vernacular nightlife zones (Campo and Ryan 2008). Often appearing in the city as the result of an agglomeration of independent small businesses, organic bar streets are not the prestigious high-end entertainment districts-such as Odaiba in Tokyo or the Cool Docks in Shanghai-that are purpose built to attract tourism and convention revenue and are relatively separate from places where urban residents work and stroll. They also are not the high-end historic ballroom, theatre, and restaurant districts celebrated in both touristic and scholarly writing (Field 2010). Rather these are often ephemeral, interstitial, and generally denigrated spaces with few obvious architectural merits or historic associations. Yet, for a time at least, they flower in the public eye, drawing crowds, attention, and (often) backlash from community stakeholders. They may become 'heritage' in that they form part of 'cumulative texture' of urban culture (Suttles 1984), being one of the iconic 'scenes' that form a city's layered character, yet they are 'grimy' in that they form in the city's unseemly 'backstage. They can be regarded as a cultural and economic resource by their patrons, but their detractors may still regard them as an eyesore. Such 'grimy heritage' is thus an example of contested urban heritage (Chang 
2000a, 2000b). Its fate usually hinges upon outsiders such as developers and government officials, though the surrounding community also plays a crucial role. Organic bar streets in Tokyo and Shanghai have much in common, but the reactions of outsiders and neighbours to their presence has differed greatly, showing differing attitudes toward these examples of 'grimy heritage' and, as a consequence, different trajectories for the development of urban nightscapes in these two cities.

\section{Conceptualising Urban Drinking Streets}

Nightlife districts are part of the urban psyche and its folk sociology. They are anonymous performance spaces for ordinary urbanites, associated with a wide variety of iconic 'characters' from the highly specific bartenders, dancers and jazzmen, to the generic 'modern girls' and 'modern boys' who crowded the dance floors. The 'modern girl'- whether the New York flapper or the Tokyo mogais a figure essential to this milieu (Weinbaum et al. 2008). Bourgeois residents in emerging global cities around the world, as early as the $19^{\text {th }}$ century, became tourists in their own cities, 'slumming' - or visiting the imagined dark spaces of the city, primarily night clubs and bars in disreputable neighbourhoods. In cities such as New York, spectacles of violence and sexual depravity were even staged for the benefit of these visitors (Heap 2008). Historically, public nightlife, as it developed in cities such as New York in the early $20^{\text {th }}$ century, allowed urban elite women to share space with working class sex workers, natives with migrants, married men and unmarried women, allowing a flagrant crossing of gender, sexual, ethnic, racial, class, generational, and other boundaries, inciting moral panic among bourgeois elites (Ehrenberg 1981). These competing desires for urban adventure and fears of urban disorder lie at the heart of the tensions in governance of urban night spaces.

In sociological research on contemporary urban nightlife streets we thus find two contrasting and even contradictory trends. On the one hand, studies (such as this one) document the development of unplanned and heterogenous nightlife zones, which I call organic nightlife streets, representing diverse impulses, activities, and interests of local actors (Jayne, Holloway and Valentine 2006; Farrer 2009; Latham 2003; Campo and Ryan 2008). Such unplanned nightlife districts become spaces of 'moral concern' because they allow 'uncontrolled contact, uncontrolled play, and uncontrolled politics'. In particular, the mixing of different types of people in nightlife can be seen as a threat to dominant social groups, who may call for a repressive response (Lofland 1991, 191). Beyond social mixing, the uncontrolled play that happens locales is also morally concerning, involving sexuality, intoxication, fantasy and escapism (Lofland 1991). Nightlife districts may be spaces for the emergence of alternative sexual subcultures (Mattson 2015) and spaces for women to enjoy time away from home (Peiss 1985; Ho 2015); but nightlife scenes may also be sites for gender violence or the harassment of women. We can add to this, the potential for grassroots urban politics that develops in these communities, either protecting them (as a type of heritage) or protesting them (as a moral or practical nuisance). In short, the organic nightlife street is often regarded as a space of disorder, which may be regarded both positively as a source of social creativity and liveliness or negatively as simply 'chaos'.

On the other hand, many studies of urban nightlife spaces show increasing gentrification, taming, and corporatisation of the nightscape in settings ranging from the UK (Chatterton and Hollands 2003) to China's mainland (Chew 2009; Farrer and Field 2015). In this story, nightlife developments are spaces of corporate profit making and monopolistic cultural governance. Moreover, even when organic nightlife streets do pop up, the response by the state and society has often been direct repression, intensified policing or the more subtle but no less effectives forms of social control through gentrification, described by one researcher as 'domestication by cappuccino' (Atkinson 2003; cited in Jayne, Holloway and Valentine 2006, 461). Or traditional organic entertainment districts may be deliberately 'themed' and 'tamed' in a way that eliminates or reduces problematic populations and activities (Chang 2000a). These two opposing dynamics-one of organic nightlife development and the other of corporatisation and taming of nightlife-are also two faces of nightlife governance, one allowing for diverse grassroots developments and the other representing a need for order and a focus on economic development.

Organic entertainment zones are generally characterised by vernacular (i.e. pre-existing local) low-grade architecture rather than purpose-built new structures. Based on a case study of North Water Street in Milwaukee Wisconsin, Campo and Ryan describe several attributes of these organic entertainment zones: narrow small buildings, diverse and understated architectures ('old' in appearance, but not 'heritage' architecture), flexible facades, no formal open spaces, continuous commercial frontage, multi-use commercial spaces, independent businesses (not chains), devotion to food and beverage establishments, 
high turnover of occupants and late-night operations. They are thus informal, low-grade, semi-public and walkable spaces that violate many of the rules of 'good urban design', lacking wide sidewalks, park spaces, uniform signage, greenery, sidewalk cafes and other elements frequently found in planned entertainment districts. Yet it is exactly this density and irregularity that create the impression of a lively urban nightscape. Such organic nightlife districts are not usually very large, and can be limited to a dozen or a few dozen venues. They can be distinguished from large-scaled, planned 'urban entertainment destinations' that often include purpose-built structures such as hotels, theme parks, large night clubs, shopping malls, theatres, museums, etc, designed to contain customers within a single corporate-managed space. Such planned entertainment districts generally are served by corporate restaurant chains, and they have been criticised for suppressing or marginalising alternative, independent and local venues (Campo and Ryan 2008).

Given that such tendencies are mixed in reality (Jayne, Holloway and Valentine 2006), we are talking here about two ideal types of the urban nightscape. On the one side, organic bar streets have an ephemeral, temporal quality and occupy seemingly marginal buildings, spaces and urban areas. They are not planned, nor initially even desired, but contribute to urban vitality (Campo and Ryan 2008). They are examples of the small scale, naturally evolving, and community-oriented urban spaces associated with affordable neighbourhoods and livable, heterogeneous spaces on a 'human scale' (Jacobs 2012; Oldenburg 1989; Zukin 2011). In contrast, larger specialised urban entertainment districts may be created specifically to limit or deny access to people seen as problematic (Chatterton and Hall 2003). In some places, corporate and mainstream night scenes exist alongside such vernacular, alternative or subcultural scenes, though the latter are arguably less valued by urban planners (Mattson 2015; Jayne, Holloway and Valentine 2006).

The situation varies across cities. A preoccupation with social disorder is particularly evident in Asian cities in which a strong developmentalist orientation is coupled with an authoritarian state, leading to the promotion of touristic and gentrified 'urban entertainment districts' while more rowdy vernacular districts may be eradicated (Chang 2000a; Chew 2009). The question that emerges from this review is how such tensions are shaping the vernacular bar streets in Shanghai and Tokyo, and what particular lessons their experience has for the development of nightlife more moving forward.

\section{Nightlife Districts and Informal Bar Streets in Shanghai and Tokyo}

Chinese cities and Japanese cities both have long histories of both informal or casual commercial drinking places and high-status and culturally recognised entertainment districts going back hundreds of years. The relatively recent development of urban bar streets, however, is a more specific post-war history. I have been conducting ethnographic fieldwork on nightlife streets in Tokyo and Shanghai for over twenty years, and this essay is based on both previous research and ongoing observations of these scenes in both cities (Farrer and Field 2015; Farrer 2009, 2016, 2019a, 2019b). The method is comparative historical ethnography. Using a few cases of bar streets in each city, I try to identify the similarities and differences in the treatment of organic bar streets and their status as a type of heritage. I begin with historic precedents and move forward to more contemporary patterns. All the discussions of contemporary bar streets are based on repeated visits to the areas, including interviews with patrons and owners, and discussions with community members effected by these bars. Historical materials are from published sources.

\section{Historical Precedents: Informal Entertainment Districts as Urban Frontier Zones}

Though their developments differ in most ways, early modern Shanghai and Edo (Tokyo) shared one feature; both were populated to a large extent by male sojourners whose families lived elsewhere. Consequently, nightlife districts flourished in both cities as centres of recreation for single men, including prostitution. By the end of the $17^{\text {th }}$ century Edo was likely the largest city in the world, with a population of one million about half of which were classified as samurai. Serving this population of male sojourners, the licensed prostitution district of Yoshiwara, a type of formalised recognised entertainment district, employed 3000 courtesans who varied in rank, income and autonomy. Many thousands more unlicensed prostitutes also worked in the city in varying degrees of servitude or indentured labour (Teruoka 1989). By 1920, Shanghai's population also had soared to over 1.5 million with a gender ratio of 135 men for 100 women. Although not formally recognised as in Edo, a major entertainment district existed in the city centre along what is now Fuzhou Road. As in Edo women employed in many entertainment-related professions, from waitresses to taxi dancers, also engaged in prostitution (Hershatter 1997, 465-466). Prostitution and sexualised entertainment were integral 
to the culture of these urban nightlife districts. As these cities grew into modern metropolises in the $20^{\text {th }}$ century, both developed edge zones or urban frontiers, with informal nightlife zones serving the needs of their vast floating male populations and employing thousands of women who themselves also were rural-to-urban migrants. Although not always literally on the edge of the city, these are spaces that represent borderlands between administrative districts or spaces that were removed from central spaces in the city.

Shanghai's first nightlife boom in the 1920s and 1930s produced a set of distinct nightlife districts, whose configuration was shaped by political boundaries. Because of the division of the city into a foreign settlement and Chinese administered zones, these were divided into insettlement districts and out-of-settlement districts. Within the International Settlement, a more formalised and regulated nightlife industry was concentrated on the roads surrounding the Recreation Ground or Race Course. The stretch of Bubbling Well Road and Nanjing Road was densely packed with ballrooms and nightclubs as was the stretch of Tibet Road and Avenue Edward VII. These were, generally speaking, the more respectable, or high-class, nightlife districts, and could be regarded as the equivalent of the high-end nightclub and entertainment zones of today (Field 2010; Farrer and Field 2015). Most of the informal bar districts, however, grew up on the edges or interstitial spaces of the city in which political and police jurisdictions were unclear. These were the nocturnal frontier zones of the city, such as the Trenches in Hongkou, Blood Alley near the Bund, or the area west of the settlements known simply as the badlands. The growth of these nightlife 'badlands' was shaped by the ways in which these districts took advantage of the complex borders between the Chinese- and foreign-administered areas of the city. Because these districts lay outside settlement boundaries or in areas of jurisdictional overlap, they had freer range to grow and develop as nightlife zones. Policing and oversight by the municipality was more problematic and less pronounced than inside settlement boundaries. Also, the proximity of the Trenches and Blood Alley to the Huangpu River made them ideal spots for sailors and other short-time visitors. These districts were infamous for drunkenness, prostitution, and barroom or street brawls.

Although administratively, there was nothing like the complex system of foreign concessions in Shanghai, Tokyo also had its nightlife frontier zones. Even the official nightlife district of early modern Edo-the red-light district of Yoshiwara-had been deliberately moved to Akasaka on the edge of the city in the $17^{\text {th }}$ century. As Shinjuku evolved into a transportation hub on the western edge of the city in the $18^{\text {th }}$ centuries, it became a zone of taverns and unlicensed brothels. With the development of the railroad in the late $19^{\text {th }}$ century, and especially after the great Kanto Earthquake of 1923 temporarily destroyed many other more central nightlife districts, Shinjuku became a prominent nocturnal destination, a space of bars, eateries, and brothels that was also an inner frontier in the city, just outside the major administrative and commercial centre and a gateway to the fast growing western suburbs. Through to the post-war period, Shinjuku was an area of sexualised entertainment, often employing women from rural areas of Japan who were sold into indentured servitude by their families (Watanabe 2016). More than any spaces in Shanghai, Shinjuku would retain its special place in the urban nocturnal geography through to the $21^{\text {st }}$ century.

By the 1930s in both China and Japan, modernising and militarising elites began to suppress nightlife, both its traditional and westernised manifestations, in the name of national renewal and military discipline. Commercial nightlife was progressively suppressed prior to Liberation and in the years after, leading to its disparition from public urban spaces, which by the end of the 1950s had disappeared from public urban spaces (Farrer and Field 2015). In Japan, the military government closed down western style jazz cafes in the 1940s while the US Occupation government insisted on first regulating, then outlawing of prostitution in the 1950s. Moreover, the US bombing of Tokyo had completely destroyed the physical infrastructure of the city. Therefore, though the details of this suppression are quite different, both cities experienced an abrupt and historic disruption in their culture of urban nightlife, with the high-status, traditional sectors virtually destroyed. When nightlife zones re-emerged in both cities, they developed in times of economic scarcity and political uncertainty and thus took the form of informal and organic bar streets that more closely resembled the nocturnal frontier zones of earlier decades.

\section{The Emergence and Survival of Organic Bar Streets in Tokyo}

In post-war Tokyo the disruption between post-war and pre-war nightlife was not as long as it would turn out to be in Shanghai, but more dramatic in some respects. The city had been obliterated by US bombing, and the American Occupation meant that for the first time in the city's history, foreigners would be, albeit temporarily, calling the 


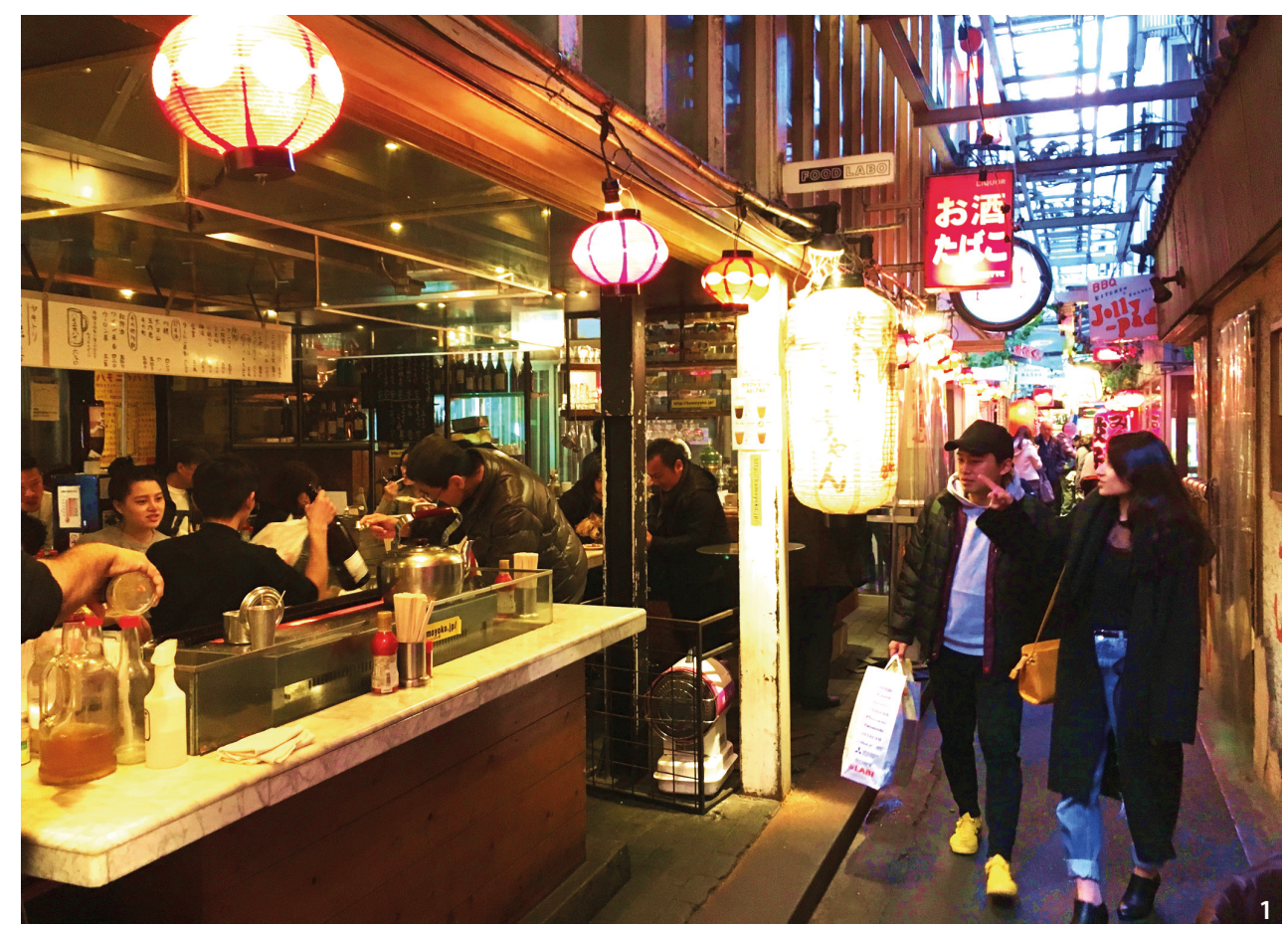

Figure 1 Kichijoji's Harmonica Yokochō is one of the most successful examples of a revived black-market bar street. (Source: the author).

shots not only politically, but even at night. The informal bar streets of post-war Tokyo developed out of the 17,000 black markets (yamiichi, or simply markets, maketto) that sprang up in bombed-out Japanese cities in the early years of the American Occupation. While they initially specialised in selling daily necessities in short supply after the war, a food and beverage business developed in most of these markets by the late 1940s. American soldiers were not only important customers but also suppliers of goods from American military supplies (Almazán and Nakajima 2013; Hashimoto 2015; Ishigure and Hatsuda 2014).

The most prominent of these nightlife districts was in Shinjuku, an area in which a black market in consumer goods had developed around the train station even before the end of the war. The earliest bars served American soldiers as well as Japanese with access to black market goods (usually from American supplies). By the late 1940s, most black-markets consisted of long rows of barracklike buildings of one or two stories, with individual stalls in the buildings ranging in size from 10 to $30 \mathrm{~m}^{2}$. An area the size of a football pitch could therefore hold a hundred small businesses. Many were hole-in-the-wall bars in which women proprietors or young female staff beckoned to customers from the doorways. A string of bars near Shinjuku Station became famous as 'harmonica yokochō' because the black openings of the long-bar looked like the openings in a harmonica (Watanabe 2008). Other areas in the city borrowed this name, including one former black-market bar district in Kichijoji called Harmonica Yokochō. Organic bar streets thrive in such places where public and private space overlaps, facilitating both sociability and flânerie (Figure 1).

As the urban areas were rebuilt in the 1950s, the black markets closest to stations often were demolished, while some were removed to other areas. As in Shanghai later, these organic bar streets were often ramshackle, informal structures, that the city officials found shameful, and thus destroyed. However, a few prominent streets have survived. The most prominent is Golden Gai (Golden Street) in Shinjuku. Like a few other post-war black markets, Golden Gai was created from the amalgamation and removal of two previous markets into an area about one kilometre from the rail station. Too far from the station for retail activities or even restaurants, most of the venues became brothels. When prostitution became illegal in 1957, many persisted as 'snack bars' with female bartenders serving food to customers, as well as accompanying customers drinking, and in later decades, singing karaoke. Gradually, Golden Gai became known as a space for the city's bohemian intellectuals or fans of cross-dressing bar owners.

With the huge increase in international tourism to Japan since 2005, the Golden Gai has emerged as a prominent international tourist attraction. Surrounding this low-rise ramshackle bar street are the modern buildings of Shinjuku, offering a much wider variety of entertainment options, including commercial sex establishments, movie theatres, chain pubs, and a famous robot-themed restaurant aimed at attracting tourists to the area. Within this larger and slowly gentrifying entertainment district (one 
Figure 2 Tourists from around the world now crowd the narrow lanes of Golden Gai in Shinjuku (Source: the author).

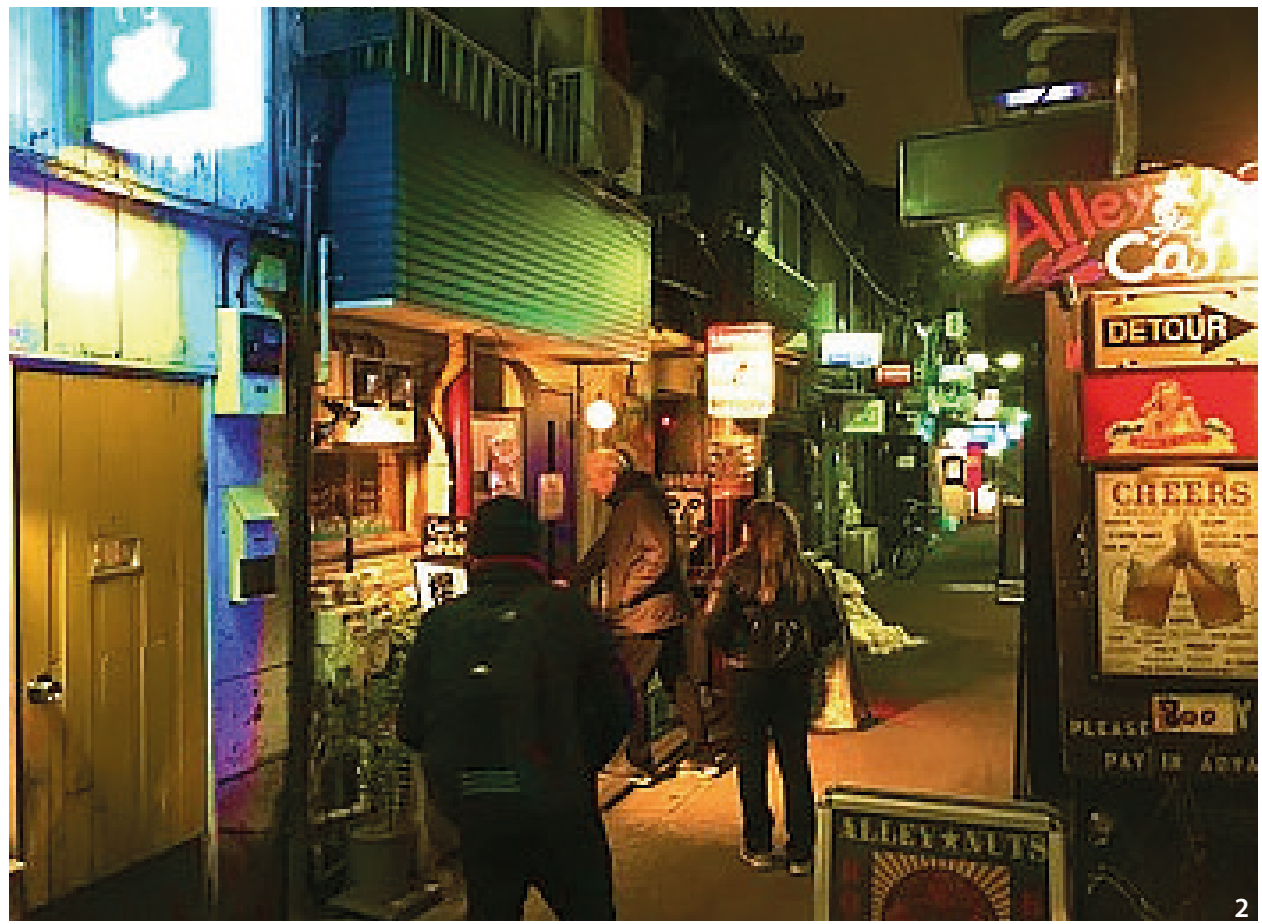

of the largest in Asia), Golden Gai is a warren of small, intimate and nostalgic spaces, that still retains the atmosphere of an organic drinking street despite the high level of tourism (Figure 2).

Overall, the story of Tokyo's informal post-war bar streets is one of their steady demolition through urban renewal through to the 1980s, and their gradual demise through the 1990s due to the fading appeal of small 'snack bars' that populated them. By the 2000s, relatively few of these post-war organic bar streets survived. However, those that have survived have come to be regarded as traditional, even iconic, Tokyo drinking streets, despite their origins under U.S. occupation and links to prostitution, bootlegging and other illegal practices (Hashimoto 2015). There is, in other words, a sense that bar streets are an essential part of Tokyo's post-war 'grimy heritage', one that many residents view with nostalgia.

They are also places of ongoing sociability. Most of the venues in these informal drinking streets were called 'snack bars' (sunakku) a term that arose to avoid regulations against late night bars enforced after the U.S. occupation. By selling food, venues were allowed to stay in business, though what many actually sold was less the 'snacks' than the companionship of the female hostesses, who sing karaoke, drink and flirt with male customers. The 'snack bar' has been described as Japan's 'nocturnal public sphere', a space in which customers communicate among themselves and with the staff in a relatively unencumbered fashion (Taniguchi 2017). Other typical venues were small family-run izakaya, which also have a very long history in Tokyo, beginning as shops selling sake and later selling foods to accompany drinks (Ino 2104). Casual, cheap and attracting both men and women, they are regarded as iconic 'third spaces: in the Japanese city' (Molasky 2014), the rough equivalent of the British pub or American saloon. Both small snack bars and izakaya are spaces for the formation of face-to-face social ties among regular customers on these bar streets.

Outside of Shinjuku, one surviving organic bar street is Willow Alley (Yanagi koji) in Nishi-Ogikubo (Farrer 2016). Much less famous than Golden Gai in Shinjuku, it is not a tourist destination, nor is it as large, but its origins lie in the same post-war milieu as a black market adjacent to the busiest commuter railway line extending West from Shinjuku. Willow Alley encompasses 45 small restaurants and bars in five buildings on the Southside of Nishiogi Station. Its two alleyways, only $2 \mathrm{~m}$ wide, are not passable by vehicles, and consists of two parallel rows of two-story 'long houses' (nagaya), a sturdy but unadorned wood-frame structure typical in post-war markets. Most shop spaces range from 14 to $30 \mathrm{~m}^{2}$ in area (including service and kitchen space). The smaller spaces of less than $20 \mathrm{~m}^{2}$ can host 5 to 10 customers at one time. Since the first floor must also accompany food preparation era, most first-floor spaces can only encompass counter seating, though a few are wide enough for a table or tables outside the doorways (Figure 3, Figure 4).

Through the 1950s to the 1980s the majority of spaces in Willow Alley were occupied by 'snack bars' (sunakku) 

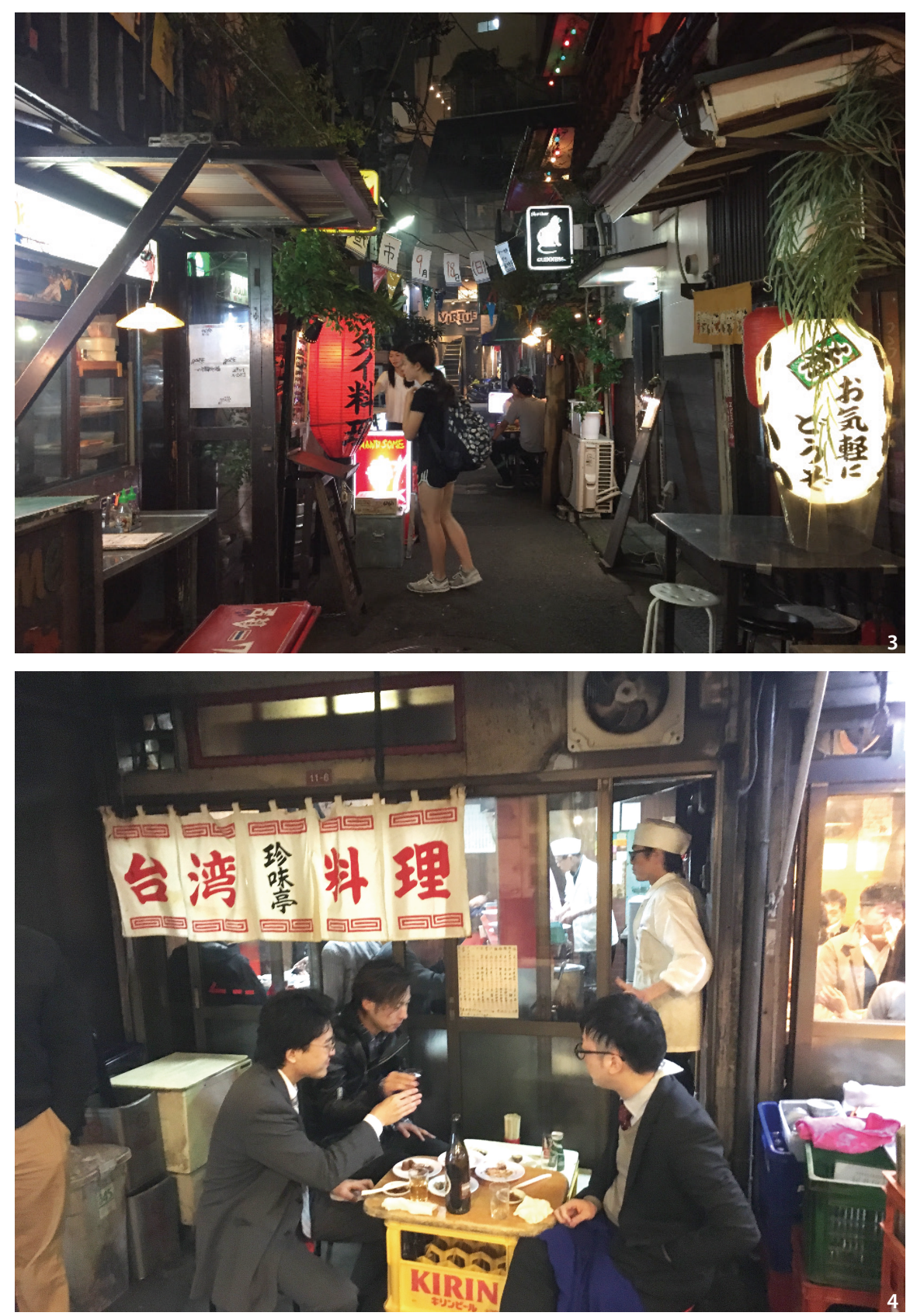

Figure 3 Visitors to Tokyo's Willow Alley Bar Street in 2017. The alleyway is too narrow for vehicles. (Source: the author).

Figure 4 People are allowed to drink in the outdoor spaces of Willow Alley, one of the vintage black market drinking streets in Tokyo (Source: the author).

managed by women proprietors. Others were family-run izakayas and noodle shops. Nowadays, there are only a few snack bars left, and the styles of bars and restaurants are much more diverse than in the past. The small scale of the spaces means that people with limited resources still can start a business, including young people, single-mothers, and foreign migrants. The small size of rental spaces also means that relatively few chain izakaya have penetrated into the area, resisting a pattern of corporatisation of nightlife common in other areas of the city (Futamura and Sugiyama 2018). Although the alleyway has a nostalgic post-war Tokyo atmosphere, several bars in Willow Alley are foreign themed and foreign owned. Women are now frequent customers as well as managers. Despite such changes, the face-to-face community structure of the bars survives. As one bar owner said, 'It is difficult to enter into such a small space and not talk to the person beside you.' She herself has created a long-term community of regulars, a common pattern on this street, in which each bar has its own ecology of regular and occasional customers (Farrer 2016) (Figure 5).

Recently, however, a group of potential investors floated a plan to redevelop the land on which Willow Alley sits. One idea would entail completely demolishing the alleyway structures. In response, local community activists started several initiatives to persuade the city government 




officials to stop such plans before they could gather momentum. One group polled all the candidates in the District Assembly election about their stance on this plan (None expressed open support). Others organised an event in June 2019 calling for residents to create their own designs for the future of the neighbourhood. At the meeting, most participants called for preserving the drinking street and created materials to send to government officials. So far, these activists are optimistic that Willow Alley can survive the threat of redevelopment, at least for now. This type of community politics-which treats Willow Alley as a positive example of local grimy heritage-is visible to district-level authorities and supports politicians also interested in preserving the alleyway structures.

Economically, Tokyo's post-war bar streets form a type of low-rise heritage architecture with touristic values. As such they face two challenges. One is the threat of demolition and redevelopment, since these are low-rise and relatively low-rent structures in high-density commercial neighbourhoods. According to a real estate agent who manages the property, one obstacle to redevelopment is the cost of removal. Land is privately owned and eminent domain law is relatively weak in Japan, meaning that developers must usually pay a high price to current occupants, especially when some oppose removal. The other threat is tourism, since many people from around the world are now drawn to these areas. In particular, inbound international tourism which has grown at a rate over 30 percent a year for the past five years, from roughly
5 million in 2000 to over 30 million in 2019 (Japan National Tourism Organisation). Tourism is not a threat to the built heritage of these spaces, but rather to the social ecology of small face-to-face communities built around regular customers. Mass tourism seems to be swamping Shinjuku's famous Golden Gai and is challenging Kichijoji's Harmonica Yokochō. However, in other less touristic organic bar streets, such as Willow Alley in NishiOgikubo, we see the survival of local community practices and also grassroots social activism aimed at preventing their physical demolition. Most importantly, because these areas have survived for over half a century, they are not only accepted by the local community but are seen as spaces for sustaining community life, despite their grimy appearance and off-colour reputation.

\section{The Emergence and Suppression of Organic Bar Streets in Shanghai}

Most of what had come to be regarded as public commercial 'nightlife' was abolished in Shanghai between the late 1950s until the Opening and Reform period that began in 1978. In the atmosphere of economic scarcity and political uncertainty in the early 1980s, nightlife zones emerged only slowly, with the first bar streets only appearing in the late 1980s and 1990s, nearly two generations after they had last flourished in the city in the late 1940s. Unlike the culture of social dance, which had spread throughout the Chinese population into the 1950s and was revived more 
broadly in the 1980s, there was thus little cultural continuity between the drinking cultures of 1940s and 1990s, which in both eras was associated with the foreign presence in the city. This perception of bars (unlike dance halls) as an alien cultural form would shape community reactions to them (Farrer and Field 2015).

From the beginning visiting foreign tourists and expatriates played an important role in the revival of Shanghai bar streets. While some famous nightclubs reopened in the 1980s as ballroom dance halls, informal bar streets generally occupied vernacular spaces that were not designed for nightlife activities, including former residential spaces, windowless storefront spaces, even former air raid shelters. These were organic developments that often abutted on residential districts and spilled into the city streets. In the 1980s, international hotels housing foreign visitors to the city were the lodestones toward which the city's reemerging nightlife would orient itself. The first nightlife district to form in the early and mid-1980s was the very small collection of 'hostess bars' and Japanese style 'snack bars' surrounding the Old Jinjiang Hotel on South Maoming Road and Changle Road, including Yesterdays, a bar that was still in operation into the 2010s. The opening of the Okura Garden Hotel in 1990 (in the space once housing the Old French Club, or Cercle Sportif Français), sent a heavily Japanese clientele to this bar (Farrer and Field 2015, 233). About a kilometre west of this district in the former French Concession, the Hilton Hotel opened in 1989 on Huashan Road and soon became another anchor for a bar street, including the famous Manhattan Bar originally located across the street from the Hilton. Bars surrounding these hotels usually hired waitresses who doubled as bar hostesses. Since these were pretty much the only show in town in the 1980s, hostess bars attracted a diverse clientele of international visitors, expatriates and some curious Chinese. However, in the eyes of most Shanghainese, these were exotic foreign spaces. This fledgling bar district relied heavily on the patronage of residents of the international hotels and seemed to have little to do with the lives of most nearby residents in the 1980s (Bao, Wang and Zhu 2001, 6).

Eventually, many of these bars moved around the corner, from Huashan Road to Julu Road, which quickly became one of the city's first organic bar streets. By the late 1990s, Julu Road included the Manhattan Bar as well as many others, such as Goodfellas, and a Mexican-themed bar called the Badlands. As on other Shanghai streets, many of the bars were in unadorned box-look structures built to provide rental income. With drunken customers reeling about on the streets and street walkers plying the strip, this section of Julu Road became an eyesore for the local government. With few exceptions, the bars of Julu Road were shut down suddenly in 2009 by authorities in the urban 'clean up' leading up to the 2010 World Expo. The flourishing and then suppression of this type of organic bar street was a pattern that we can see again and again in Shanghai.

The most famous and illustrative example of this pattern might be South Maoming Road. Between 1996 and 1999, South Maoming Road in the former French Concession, between Fuxing Road and Yongjia Road, was transformed from a quiet leafy residential street into the city's most bustling bar street and, by many accounts, the most exuberant and colourful nightlife zone in the city's recent history. Unlike the unplanned nightlife districts in post-war Shinjuku, Shanghai's most famous organic bar street did not develop in a bombed-out urban wasteland, but rather in a confusing mix of heritage architecture redolent with nightlife history mixed in with temporary buildings specifically erected for turning a quick profit in the bar business.

One example is the bar Judy's Too which was opened by a female nightlife entrepreneur in August 1996 in a quiet, plane-tree lined section of South Maoming Road located between Fuxing Road and Yongjia Road. This area was the site of the famed Canidrome racetrack and ballroom (Farrer and Field 2015, 235). Soon after its opening in 1996, Judy's Too became a hot dance club on busy nights, attracting roughly equal numbers of Chinese and foreign patrons. Though small by the standards of urban Shanghai discos, the dance floor would inevitably be jam-packed with revelers on a Friday or Saturday night. With the success of Judy's Too, other bars like the American-owned Blue Frog (now a popular restaurant chain) and the Australian-owned DKD soon followed her to South Maoming Road. Over the next five years, dozens of bars and cafes opened and closed on this section of South Maoming Road, reaching about fifty total. By the dawn of the new millennium, the street had become a noisy contact zone of mixed-class and interethnic interactions, which echoed the 1920s interzones of the Trenches and Blood Alley in its reputation for sexual license and social disorder. In the summers of 1999 and 2000, on a weekend night thousands of customers and dozens of cabs clogged the street. Some bars featured live bands, and most had spaces for dancing. During the warmer months, many of the bars fronted the street with open air seating allowing patrons to watch the nocturnal flow of cars and people in Parisian café style. This visual panorama included not only fashionable bar 
customers, but a whole array of actors engaged in illegal activities, among whom frequent outbursts of conflict arose, requiring the intervention by the police (Field and Farrer 2015, 237) (Figure 6).

Local government agents struggled with the perceived social disorder on South Maoming Road . In a heavyhanded 'strike hard' (yanda) campaign against drugs and prostitution in 2000, police closed down almost all the bars on Maoming Road and Julu Road. In the summer of 2003, police cracked down on the bar street again, focusing on noise violations. New regulations forced bars to close at 2:00 a.m. and banned open-air music. Panicking over the second shut-down in three years, many of the bars and clubs of South Maoming Road began to move over to a new location on Tongren Road. The fate of Shanghai's most famous organic bar street was sealed. In 2006, the original Canidrome Hotel building was razed to make way for a new structure, which opened in 2010 as a theatre. Meanwhile, all of the temporary buildings on the western side of the street that had housed the lively bars and clubs of South Maoming Road were destroyed. The once boisterous bar street was gone and replaced with a staid urban cultural centre.

Though no other organic bar streets would match the scale and rowdiness of South Maoming Road, this story would repeat itself on other organic bar streets that would emerge throughout the city in the boom years of economic growth in Shanghai. Rowdy bar streets flourished on Tongren Road in the early 2000s, Yongfu Road in the later 2000s, and Yongkang Road in the mid-2010s. All were in residential areas of the central city, and all attracted dozens of small-scale nightlife entrepreneurs, including many migrant entrepreneurs from other countries and other Chinese provinces. The initial customers on these Shanghai nightlife streets were often young expatriates, but over time, patronage tended to localise, with many Shanghainese becoming regulars at bars opened initially for foreign migrants. However, before any of the streets could settle into a comfortable 'middle age' of steady (and less noisy) customers we see in Tokyo bar streets, they would be closed down. Like South Maoming Road, all fell victim to the twin forces of urban redevelopment and the desire of the city officials to eliminate public disorder (Figure 7).

A key difference with Tokyo was the attitude expressed by local residents. Unlike the situation in Tokyo, the reappearance of drinking streets in Shanghai were not regarded by many local residents as a re-emergence of indigenous urban culture, but rather as an invasion of alien cultural practices. On Maoming, Julu and Yongkang
Road, complaints were lodged to local officials (including, according to some reports, high ranking officials). Some residents on Yongkang Road even took to opposing the noisy bar patrons by dumping water on them from upstairs windows (Li 2013). Although arguably as much a part of Shanghai's urban mythos as it is in Tokyo, this type of 'grimy heritage' was not vocally supported by local residents. If community support did exist, it did not take an organised form, unlike Tokyo's Willow Alley.

Shanghai officials clearly favoured developments that kept nightlife separate from residential areas, not an unreasonable goal given the voices of local residents. Moreover, as Shanghai began more strictly enforcing noise, fire and other regulations, many street front venues were found to be in violation of environmental rules. Such strict regulations prioritise large-scale projects with modern corporate-scale venues in planned entertainment districts. Moreover, eminent domain is strong in China where land is publicly owned. In Shanghai, the city has repeatedly removed older structures (and residents) to make room for new commercial developments. These include massive entertainment zones based on historic architecture, such as Xintiandi (Ren 2008), or redevelopments of underused urban infrastructure, such as the Cool Docks in former riverfront warehouses and Found 158 in a space of former bomb shelters that had been redeveloped multiple times. Although areas such as the Cool Docks and Found 158 aimed to create an atmosphere of urban cool, they have many of the characteristics of planned commercial nightlife zones described in other cities: high rents that exclude small independent operators, and high prices that exclude many types of customers. The uniform design and the absence of small independent operators produces a sanitised and uniform space aimed at middle-class and upper-class urbanites. Shanghai now features many planned nightlife districts, but it remains unclear if the city will ever again tolerate the growth of rowdy organic bar streets such as Maoming Road.

\section{Conclusions: A Case for Grimy Heritage}

Shanghai and Tokyo both have a grimy heritage in the form of vernacular, or organic nightlife zones that go back to their origins as modern cities. In both cities there was a synergistic tie between a disproportionately large floating population of male sojourners and another large floating population of women working in these informal nightlife districts. Whether in the early $20^{\text {th }}$ century or early $21^{\text {st }}$ century, these are urban frontiers in which we find drunkenness, drug dealing, public soliciting for business 

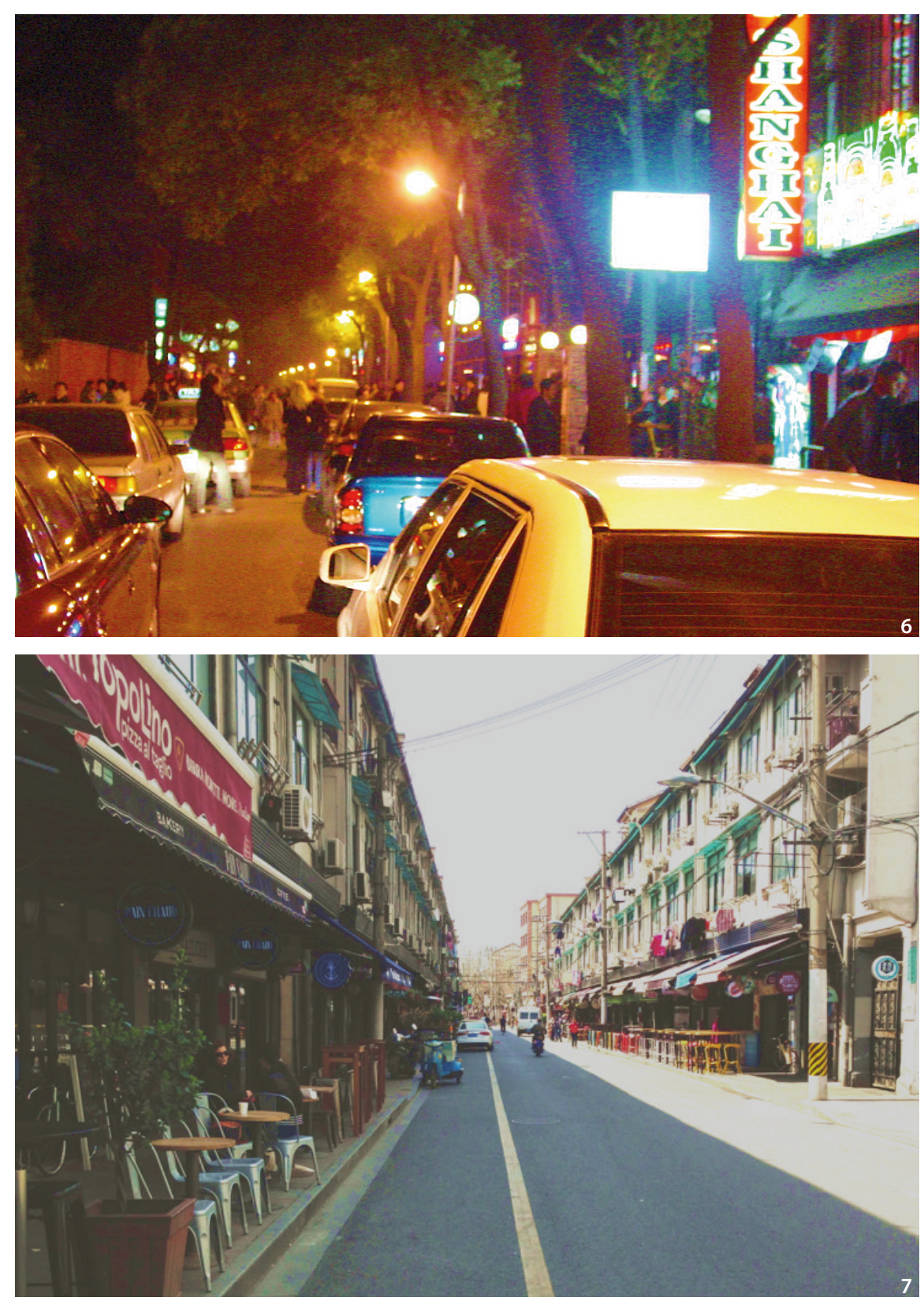

Figure 6 Traffic jams were one common complaint among visitors and area residents on South Maoming Road in summer 2000 (Source: the author).

Figure 7 At its height of activity in 2013 small bars lined both sides of the street on Yongkang Road. Quiet in the daytime, at night customers spilled into the street (Source: the author).

or prostitution, brawling, noisy behaviour, disorderly traffic, illegal street vending, street crime, and other forms of public nuisance. The barrack-like structures of the Shinjuku night markets and one- and two-story street-front shop stalls housing the small bars along Shanghai streets shared a quality of being unremarkable, unadorned or simply ugly. Although some bars in Reform-Era Shanghai temporarily occupied vintage buildings, most of the physical structures of its organic drinking streets were jerrybuilt and utilitarian. Or they were the ground floor apartments of buildings not designed for food service. These were not the gorgeous dance palaces of the 1930s nor the VIP dance clubs of the 2010s. While the soldiers and sailors are gone, the $21^{\text {st }}$-century agents of 'disorder' are often associated with mass tourism, business travel, and partying urban youth. It is no wonder that cities seldom cherish this grimy heritage, and not only city officials, but many local residents, are happy to close them down. However, when allowed to survive, as in Willow Alley in Tokyo, they may become integrated into local urban identity and are supported by local residents as urban heritage.

This comparative overview of organic drinking streets in two of Asia's largest cities implies a case for historical and sociological value of this type of grimy heritage, one that may or may not be recognised by local residents. Like their historical predecessors in the pre-war era they tend to be urban frontiers in a sense that they are places of boundary crossings that are moral, sexual, and cultural. 
People from different economic and cultural backgrounds meet and mix in these heterogenous cultural zones that include venues with very different subcultural orientations. They are thus culturally productive and transgressive and usually regarded both by their supporters and detractors as spaces of individual freedom and cultural creativity. Local residents may feel like outsiders in these scenes, fostering opposition (Campo and Ryan 2008; Latham 2003; Jayne, Holloway and Valentine 2006).

Unlike planned nightlife zones, however, organic nightlife streets tend to provide inexpensive points of entry into nightlife culture for both patrons and owners. For young patrons, they allow men and women to play on an equal footing. Poor young men are not excluded by the prices, and poor young women do not have to look to the patronage of men to afford a night out (as they often must do in expensive nightclubs). The scale of these spaces also matters in other ways. Smaller bar spaces like those on Shanghai's Julu Road in the 1990s or in Tokyo's Willow Lane in 2010 were available to young and novice entrepreneurs wishing to start a small independent nightlife business. In both places these entrants included many single women and international migrants, who then contributed to community development. Organic bar streets are thus cosmopolitan communities in which foreigners may become key members, unlike most other urban places in Shanghai and Tokyo (Farrer 2019a, 2019b). The human scale of these bar spaces also matters in terms of the capacity to sustain social interactions. They are more likely to create a community of regulars who stay connected with one another, as they do in Tokyo's Willow Alley. When such bar streets disappear, however, the ephemeral communities they support also disappear with them. This case for 'grimy heritage' is therefore not only a case for recognising the past existence and historical importance of these spaces but also for the positive social values they may embody in the present (while not denying some of the negative social attributes described above). These positive values of organic bar streets include accessibility, diversity, creativity, and community.

The forces allayed against organic bar streets are great. City governments don't like them for practical administrative reasons: they are cheap and disorderly, bringing little tax revenue while requiring policing. To both bureaucrats and developers, upscale nightlife developments are a more profitable and manageable strategy. In Shanghai, in particular, organic nightlife street have little community support, and have been repeatedly closed down. The factors that sustain them in Tokyo are threefold: (1) Private ownership of land and weak eminent domain powers in Japan entail that redevelopment in Tokyo is a more expensive and complex than in Shanghai, and opposition from civil society actors, tenants and land owners can delay it for years. (2) Grassroots community organisation in Tokyo means that patrons, owners and community supporters may organise more freely to protect threatened districts, as we saw in the case of Willow Alley. (3) Perhaps the most important is that unlike in Shanghai, these bar streets are regarded as authentic local heritage by many local residents. Many Shanghainese, on the other hand, have regarded bar streets as a foreign import with little connection to their lifestyles. Ultimately corporatisation and gentrification threaten organic bar streets in Tokyo as well, but in the meantime, these factors sustain them in some areas of the city.

\section{References}

Almazán, J. and Yoshinori, N., 2013. "Urban Micro-Spatiality in Tokyo: Case Study on Six Yokochō Bar Districts.” Transactions of AIJ. Journal of architecture, Planning and Environmental Engineering 78 (689): 1515-1522.

Bao, Yaming, Hongtu Wang, and Shengjian Zhu. 2001. Shanghai jiuba: kongjian, xiaofei yu xiangxiang [Shanghai Bars: Space, Consumption and Imagination]. Nanjing: Jiangsu People's Press.

Campo, Daniel, and Brent D. Ryan. 2008. “The Entertainment Zone: Unplanned Nightlife and the Revitalization of the American Downtown." Journal of Urban Design 13 (3): 291-315.

Chang, Tou Chuang. 2000a. "Theming Cities, Taming Places: Insights from Singapore.” Geografiska Annaler: Series B, Human Geography 82 (1): 35-54.

Chang, Tou Chuang. 2000b. "Singapore's Little India: a tourist attraction as a contested landscape." Urban Studies 37 (2): 343-366.

Ehrenberg, Lewis A. 1981. Steppin' Out: New York Nightlife and the Transformation of American Culture. University of Chicago Press.

Farrer, James, and Andrew Field. 2015. Shanghai Nightscapes: A Nocturnal Biography of a Global City. Chicago: University of Chicago.

Farrer, James. 2009. "Shanghai Bars: Patchwork Globalization and Flexible Cosmopolitanism in Reform-era Urban Leisure Spaces." Chinese Sociology and Anthropology 42 (2): 22-38.

Farrer, James. 2016. "Nishiogology: Tokyo Urban Studies Research.” Accessed 10 September 2019. https://www. nishiogiology.org

Farrer, James. 2019a. "Culinary Globalization from Above 
and Below: Culinary Migrants in Urban Place Making in Shanghai." In Immigration to China in the Post-reform Era: Destination PRC, edited by Angela Lehmann and Pauline Leonard, 175-199. New York: Palgrave Macmillan.

Farrer, James. 2019b. International Migrants in China's Global City: The New Shanghailanders. Abingdon: Routledge.

Field, Andrew. 2010. Shanghai's Dancing World: Cabaret Culture and Urban Politics, 1919-1954. Hong Kong: Chinese University Press.

Futamura, Taro, and Kazuaki Sugiyama. 2018. “The Dark Side of the Nightscape: The Growth of Izakaya Chains and the Changing Landscapes of Evening Eateries in Japanese Cities." Food, Culture \& Society 21 (1): 101-117.

Hashimoto, Kenji. 2015. Izakaya no Sengoshi [Postwar History of Izakaya]. Tokyo: Shodensha.

Heap, Chad. 2008. Slumming: Sexual and Racial Encounters in American Nightlife, 1885-1940. University of Chicago Press.

Hershatter, Gail. 1997. Dangerous Pleasures: Prostitution and Modernity in Twentieth-Century Shanghai. Univ of California Press.

Ho, Swee-Lin. 2015. “License to drink': White-collar Female Workers and Japan's Urban Night Space." Ethnography 16 (1): 25-50.

Ino, Ryoichi. 2014. Izakaya no dansei: Edo no nomi daorebunka [The Birth of the Izakaya: The Drink till You Drop Culture of Edo]. Tokyo: Takuma Gakugeibunku.

Ishigure, Masakazu, and Kosei Hatsuda. 2014. “'Shinkoichibachizu’ ni miru sengō Tokyo no makketto no kenchiku bunseki” [Architectural Analysis of the Markets of Postwar Tokyo Seen in the "Shinkou Ichiba Map".] Transactions of AIJ. Journal of Architecture, Planning and Environmental Engineering.

Jacobs, J.M., 2012. "Urban Geographies I Still thinking Cities Relationally." Progress in Human Geography 36 (3): 412-422.

Jayne, Mark, Sarah L. Holloway, and Gill Valentine. 2006. "Drunk and Disorderly: Alcohol, Urban Life and Public Space." Progress in Human Geography 30 (4): 451-468.

Latham, Alan. 2003. "Urbanity, Lifestyle and Making Sense of the New Urban Cultural Economy: Notes from Auckland, New Zealand.” Urban Studies 40 (9): 1699-1724.

Li, Hao. 2013. "Angry Shanghai Residents Dump Water on Noisy Foreigners." China Smack. Accessed 10 September 2019. https://www.chinasmack.com/angryshanghai-residents-dump-water-on-noisy-foreignersyongkang-road
Lofland, Lynn. 1991. “The Urban Milieu: Locales, Public Sociability, and Moral Concern." In Social Organization and Social Process: Essays in Honor of Anselm Strauss, edited by David R. Maines, 189-205. Piscataway, NJ: Aldine Transaction.

Mattson, Greggor. 2015. "Bar Districts as Subcultural Amenities." City, Culture and Society 6 (1): 1-8.

Molasky, Michael. 2014. Nihon no Izakaya Bunka: Akachochin no Miryoku wo Saguru [Japan's Izakaya Culture: Exploring Fascination of Red Lantern]. Tokyo: Kobunsha Shinsho.

Oldenburg, Ray, 1989. The Great Good Place: Café, Coffee Shops, Community Centers, Beauty Parlors, General Stores, Bars, Hangouts, and How They Get You through the Day. Saint Paul, MN: Paragon House Publishers.

Peiss, Kathy Lee. 1985. Cheap Amusements: Working Women and Leisure in New York City, 1880 to 1920. Philadelphia, PA: Temple University Press.

Quora. 2013. “Is Singapore too Sterile?” Accessed 10 September 2019. https://www.quora.com/Is-Singaporetoo-sterile

Ren, Xuefei. 2008. "Forward to the Past: Historical Preservation in Globalizing Shanghai." City \& Community 7 (1): 23-43.

Suttles, Gerald D. 1984. “The Cumulative Texture of Local Urban Culture." American Journal of Sociology 90 (2): 283-304.

Taniguchi, Koichi. 2017. Nihon no yoru no kōkyō-ken: Sunakku kenkyū josetsu [Japan's Nighttime Public Sphere: An Introduction to Snack Research]. Tokyo: Shiromizusha.

Teruoka, Yasutaka. 1989. “The Pleasure Quarters and Tokugawa Culture.” In Eighteenth Century Japan: Culture and Society, edited by C. Andrew Gerstle, 3-32. London: Routledge.

Watanabe, Hidetsuna. 2016. Shinjuku Gorudengai Monogatari [The Gtory of Shinjuku Golden Gai]. Tokyo: Kondansha.

Weinbaum, Alys Eve, Lynn M. Thomas, Priti Ramamurthy, Uta G. Poiger, Madeleine Yue Dong, and Tani E. Barlow, eds. 2008. The Modern Girl Around the World: Consumption, Modernity, And Globalization. Duke University Press.

Zukin, Sharon. 2011. Naked City: The Death and Life of Authentic Urban Places. Oxford: Oxford University Press. 